\title{
Gender differences in smoking behavior and cessation
}

\author{
Susan E. Chaney * Susan W. Sheriff, Linda Merritt \\ The Houston J. and Florence A. Doswell College of Nursing, T. Boone Pickens Institute of Health Sciences, Texas Woman's \\ University, Dallas, United States
}

Received: August 27, 2014

Accepted: March 8, 2015

Online Published: March 12, 2015

DOI: $10.5430 /$ cns.v3n3p17

URL: http://dx.doi.org/10.5430/cns.v3n3p17

\begin{abstract}
Objective: Many women want to quit smoking, but have lower abstinent rates than men. The gender differences in smoking behaviors and cessation in adults were explored through qualitative analyses of individual interviews with male and female smokers.

Methods: Sixty-one participants (34 men and 27 women), who reported using tobacco within the last year, completed open-ended phone interviews concerning barriers faced during smoking cessation. Participants reported smoking for an average of $23.0(S D=$ $11.3)$ years and making an average of $2.41(S D=2.6)$ prior quit attempts. The interviews were transcribed and analyzed using qualitative content analysis procedures. An investigator external to the study independently analyzed qualitative interview data to increase the trustworthiness of results.

Results: Barriers relating to stress-mood regulation and social factors (e.g., others smoking) were most commonly reported in both genders ( $72 \%$ \& $41 \%$ respectively). However, women tended to report a greater number of distinct barriers $($ Cohen's $d=0.4)$ and a great frequency of stress-related factors and anxiety. Factors related to the sensory aspects of smoking were more common among women and only women noted the lack of social support as a barrier. Other barriers included use of alcohol and factors related to the addictive nature of tobacco use (e.g., cravings). Abrupt cessation, or "cold-turkey", was most common cessation method for both genders. However, both men and women reported using a variety of smoking cessation methods including nicotine replacement, cessation medications, electronic cigarettes, and behavior strategies.

Conclusions: The results showed that barriers to smoking cessation differed between the genders. Implications for smoking cessation programs include gender specific interventions.
\end{abstract}

Key Words: Smoking cessation, Gender differences, Qualitative research

\section{INTRODUCTION}

In the United States, 480,000 people will die due to a smoking related illness every year. For every one of these deaths, thirty-three smokers will suffer from a disease in which smoking is a contributing factor. These factors make the use of tobacco the single largest, preventable cause of death and disease in this country. ${ }^{[1]}$ Despite these facts, it is estimated that 42.1 million people over the age of 18 continue to smoke. ${ }^{[1]}$ Two out of three smokers report they want to quit and the majority of them are women. However, half of smokers who try to quit will take multiple attempts without success. ${ }^{[2]}$ With many women expressing a desire to quit, understanding the gender differences in smoking behaviors and cessations will help tailor treatments for smoking cessation. In turn, these tailored treatments should improve the smoking cessation rate.

\subsection{Literature review}

According to the American Lung Association, ${ }^{[3]} 21.1$ million women smoke compared to 24.8 million men, but women have a greater chance of having a smoking-related illness.

*Correspondence: Susan E. Chaney; Email: schaney@twu.edu; Address: The Houston J. and Florence A. Doswell College of Nursing, T. Boone Pickens Institute of Health Sciences, 5500 Southwestern Medical Avenue, Texas Woman's University, Dallas, TX, 75235, United States. 
Although the reasons why women are at greater risk of a smoking-related illnesses are still unknown, "researchers suggest physiological differences between the sexes, or perhaps because women smoke differently than men, means women are more strongly affected by the cancer-causing chemicals in tobacco smoke". ${ }^{[4]}$ When women do quit, they are usually less successful than men and are at an elevated risk for relapse. ${ }^{[5]}$ Women tend to relapse and lag behind men on smoking cessation success rates due to fear of gaining weight. Women have been shown to use smoking as a weight-loss tool through appetite suppression. ${ }^{[6]}$ Research has shown that smokers' inability to stop smoking is due to a variety of causes (i.e. addiction, habit, continued stress), but these causes do differ between the genders. ${ }^{[7]}$ Men, usually, have more success with nicotine replacement therapy and staying abstinent. ${ }^{[2]}$ They report restarting smoking because they see a cigarette and want it, or because their nerves were on edge. ${ }^{[8]}$ Research has shown that women report having greater cravings in response to the negative effects of stress. In fact, negative emotional experiences were linked to craving a cigarette. ${ }^{[9]}$ Pineiro, Lopez-Duran, Fernandez del Rio, Martinez, and Becona ${ }^{[10]}$ examined 288 smokers who received cognitive-behavioral treatment for smoking cessation. The researchers assessed the personality patterns of smokers seeking smoking cessation treatment. The authors concluded that there are different reasons for smoking in men and women. Women smoked more for tension reduction/relaxation, stimulation and social reasons than men.

Researchers have reported reasons for starting smoking again are because of being ostracized by their friends who smoke, lack of enjoyment, and stress from outside sources. ${ }^{[1,12]}$ Even knowing the reasons, women continue to achieve lower abstinence rates than men. ${ }^{[2]}$ Recent reviews of the qualitative literature on barriers to smoking cessation have failed to include analysis of gender differences. ${ }^{[13]}$ In addition, recent work in this area has relied on closed-ended survey methodology. ${ }^{[14]}$ Additional research is needed to replicate and elaborate on differences in the barriers women and men face in order to tailor programs based on gender.

\subsection{Purpose}

The purpose of this article is to present the findings from an interview study designed to examine the gender differences in smoking behaviors and cessation in adults. It is important to understand the differences so that treatment can be matched to the gender specific barriers identified for more effective smoking cessation strategies.

\section{Methods}

The Institutional Review Board of researchers' university approved all study procedures.

\subsection{Design}

This is a qualitative, descriptive study based on the individual interviews of male and female smokers. Content analysis was used to gain insight the differences between men and women in methods used and barriers faced when trying to quit smoking. Counselors asked a series of the same questions to each individual subject. The design was specifically chosen because the literature about the gender differences in regard to smoking behaviors and cessation was limited by the reliance on quantitative methods.

\subsection{Participants}

A convenience sample was recruited from community members. A total of 61 participated in the study, 34 males and 27 females. Participants were randomly recruited from the Dallas/Fort Worth metropolis through local newspapers, websites, and community centers. The eligibility criteria were: 1) age 19 years or older; 2) self-reported use of tobacco in any amount for at least the past year; 3) ability to read, understand, and communicate in English; 4) and be willing to participate in one telephone interview for a counseling/support session.

\subsection{Data collection}

The researchers advertised for participants and recruited via the local newspapers and websites in a large metropolitan city in the southwestern region of the United States. Potential participants telephoned the researchers, listened to a script describing the study, and gave oral informed consent. The participants left their phone numbers so they could be phoned by the substance abuse counselor.

The substance abuse counselor conducted a fifteen minute phone interview with the participants. Participants were asked about basic demographic characteristics (see Table 1). Subsequently, participants were asked a series of questions about their current smoking behaviors, tobacco use history, and motivation and confidence to quit smoking now. Openended questions included: "What methods did you use in your previous quit attempts?"; "What barriers did you face during smoking cessation?"

Two of the initial participants withdrew their consent after being contacted. All those who agreed to participate received a \$25 Wal-Mart gift card. Data was collected in a fixed point in time and relied on retrospective accounts of smoking history and amount of smoking. The phone interviews were audio-taped and transcribed by two graduate assistants.

\subsection{Data analysis}

Closed-ended questions were summarized using traditional quantitative techniques to provide a description of the sam- 
ple of smokers. Motivation and confidences to quit smoking were coded from the transcripts on a 0-3 scale with higher values indicating greater motivation and confidence to quit.
Differences between males versus females were assessed using a $\chi^{2}$ test for categorical variables and a $t$-test for continuous variables.

Table 1. Participant demographic characteristics for male and female smokers interviewed

\begin{tabular}{|c|c|c|c|c|}
\hline \multirow{2}{*}{ Characteristics } & \multicolumn{2}{|c|}{ Males } & \multicolumn{2}{|c|}{ Females } \\
\hline & $n$ & $\%$ & $n$ & $\%$ \\
\hline \multicolumn{5}{|l|}{ Age } \\
\hline $19-35$ & 9 & 26.5 & 11 & 40.7 \\
\hline $36-55$ & 20 & 58.8 & 12 & 44.4 \\
\hline 55 and over & 5 & 14.7 & 4 & 14.8 \\
\hline \multicolumn{5}{|l|}{ Ethnicity } \\
\hline White & 16 & 47.1 & 15 & 55.6 \\
\hline Black & 18 & 52.9 & 12 & 44.4 \\
\hline \multicolumn{5}{|l|}{ Education } \\
\hline Less than High School & 4 & 11.8 & 2 & 7.4 \\
\hline High School Diploma or GED & 20 & 58.8 & 14 & 51.9 \\
\hline More than High School & 10 & 29.4 & 11 & 40.7 \\
\hline \multicolumn{5}{|l|}{ Income Level - Yearly ${ }^{*}$} \\
\hline Less than $\$ 15000$ & 16 & 47.1 & 12 & 46.2 \\
\hline$\$ 15000-\$ 29000$ & 7 & 20.6 & 5 & 19.2 \\
\hline More than $\$ 29000$ & 11 & 32.4 & 9 & 34.6 \\
\hline \multicolumn{5}{|l|}{ Married ${ }^{*}$} \\
\hline Single & 17 & 50.0 & 18 & 66.7 \\
\hline Divorced & 10 & 29.4 & 6 & 22.2 \\
\hline Married & 7 & 20.6 & 3 & 11.1 \\
\hline
\end{tabular}

${ }^{*}$ Some participants declined to report demographic information for this variable.

All 61 interviews were analyzed using a qualitative content analysis. ${ }^{[15,16]}$ The two primary investigators (SS \& SC) preformed an initial analysis inductively, focusing on the manifest content. The transcribed interviews were first read in their entirety to obtain an overall sense of the participant's responses. Subsequent abstraction focused on specific responses to methods used to quit and barriers faced during smoking cessation. Text was divided into meaningful units and categories were generated for responses to each of the major themes (methods used to quit, barriers to quitting).

Subsequently, an external consultant (JEG) provided an independent qualitative content analysis of the transcripts. This investigator was blind to gender status during the early stages of content analysis. This additional analysis provided a method to increase the trustworthiness of the results and utilized both a deductive and inductive approach. ${ }^{[17]}$ Key concepts were drawn from previous qualitative work on barriers to smoking cessation ${ }^{[13,18]}$ and guided the creation of code labels for participant's responses. After initial identification of labels, codes were validated by iteratively examining transcripts to ensure all meaningful units were categorized appropriately. Final coding of responses was discussed by the whole research team to arrive at consensus. There was complete agreement between investigators with respect to the major content categories coded from the interviews. Quotations of representative text are presented in the Results section.

After coding of the interview data was completed, results were analyzed comparatively between male versus female smokers. Quantitative analysis of the frequency of content codes for men versus women utilized a $\chi^{2}$ test for categorical variables.

\section{Results}

\subsection{Demographic characteristics}

Demographic characteristics are presented in Table 1 for men versus women smokers participating in the interviews. There were slightly more males $(n=34,55.7 \%)$ than females $(n=$ $27,44.3 \%)$. The majority had less than a college education $(n=40,65.6 \%)$ and made less than $\$ 14,999(n=28,46.7 \%)$. 
African Americans represented 49\% of the participants. Chisquared analyses failed to reveal any significant differences in demographic characteristics between men and women (all $p>.3)$.

\subsection{Tobacco use characteristics}

Smoking characteristics of male and female participants is presented in Table 2. These participants smoked an average of $16.6(S D=7.7)$ cigarettes per day and had smoked for an average of $23.0(S D=11.3)$ years. Participants had made an average of $2.41(S D=2.6)$ prior quit attempts. In general, motivation to quit was high across participants (mean = 2.87 out of $3, S D=0.6$ ), while confidence to quit was more moderate $($ mean $=1.9, S D=1.3)$. Compared to women, men appeared to report smoking more per day for a longer time period, but these differences were only marginally significant $(\mathrm{F}>3, p<.1)$.

Table 2. Smoking characteristics for male and female participants

\begin{tabular}{llllll}
\hline \multirow{2}{*}{ Smoking Characteristics } & \multicolumn{2}{c}{ Males N = 34 } & & \multicolumn{2}{c}{ Females N = 27 } \\
\cline { 2 - 3 } \cline { 5 - 6 } Cigarettes per day & Mean & (St. Dev.) & & Mean & (St. Dev.) \\
Years Smoking & 18.2 & $(7.6)$ & $(14.5)$ & $(8.7)$ \\
Prior Quit Attempts & 25.2 & $(12.5)$ & 20.1 & $(2.3)$ \\
Number Smoking Family & 2.6 & $(2.7)$ & $(2.4)$ & 2.2 & $(1.9)$ \\
Motivation to Quit $^{*}$ & 2.4 & $(0.3)$ & & 2.2 & $(0.8)$ \\
Confidence to Quit $^{*}$ & 2.9 & $(1.3)$ & 2.0 & $(1.3)$ \\
\hline
\end{tabular}

" On a 0-3 scale, with high scores indicating greater levels.

\subsection{Barriers to smoking cessation}

Five major factors were identified as barriers to smoking cessation: stress-mood regulation, hedonics-sensory enjoyment, social, other drug use, and addiction-habit. With respect to gender differences in the total number distinct barriers, women tended to report greater number of barriers (mean = $1.6, S D=0.8)$ compared to men $($ mean $=1.3, S D=0.8)$.

\subsubsection{Stress-mood regulation}

The stress-mood regulation category consisted of subcategories for stress, anxiety, depressed mood, and boredom. This category of barrier was commonly reported for both men and women with $\mathrm{N}=44(72.1 \%)$ of the sample having a response coded in this category. Representative responses include "The more stress I have, the more I smoke" (stress) and "I have been worrying a lot for quite a while and that has contributed to my smoking" (anxiety). Women tended to report a greater number of distinct stress-related barriers than men $($ mean $=0.96, S D=0.6$ for women and mean $=0.76$, $S D=0.7$ for men, effect size $=0.3$ ). In particular, anxiety was more commonly endorsed by women ( $14.8 \%$ vs. $5.9 \%$ ).

\subsubsection{Hedonics-sensory enjoyment}

The sensory enjoyment category captured responses relating to the enjoyment of the sensory aspects of cigarette smoking. Representative responses include "miss the taste", "oral fixation", and "smell". These types of responses were more common among women versus men (7.4\% vs. $2.9 \%)$.

\subsubsection{Social factors}

Barriers related to social factors consisted of two important sub-categories. One prominent sub-category involved the influence of other smokers, with $\mathrm{N}=25(41 \%)$ of the sample having a response in this category. Representative responses include "If everyone around me would not smoke, I could." and "Every time I am around someone smoking, I have to smoke." A common textual unit was "others smoking”. A second, less common, factor involved the lack of social support from others. The common textual unit was "no support". The lack of social support was only reported by female smokers.

\subsubsection{Other alcohol or drug use}

Although less common, use of alcohol and other drugs was a barrier for both men and women, with $6.6 \%$ of the respondents discussing this issue. Common textual units referred to the "drinking" and "alcohol". This barrier was commonly expressed in context of social factors. For example, responses referenced "social drinking". One response noted: "Somebody comes over your house with a six pack and a pack of cigarettes... The next thing you know you are at the store buying a pack of cigarettes."

\subsubsection{Addiction - habit}

Another less common factor involved references to the addictive nature of tobacco use, with $6.6 \%$ of the participants describing this type of barrier. Sub-categories included references to withdrawal symptoms, cravings, and habitual/compulsive aspects of tobacco use. Textual units refer- 
enced "cravings", "withdrawal", and "habit". Men appeared to include responses in this category more than women.

\subsection{Smoking cessation methods}

Several methods for quitting smoking were reported by participants. Abrupt cessation, or "cold-turkey" was a common method with $\mathrm{N}=38$ (62.3\%) listing this in their responses. Both men $(14.7 \%)$ and women $(25.9 \%)$ reported using a range of nicotine replacement products, including nicotine gum, patch, and lozenge. Both genders also gave responses indicating the use of electronic cigarettes "E-cigs" as an aid in smoking cessation. Other cessation medications included "Chantix". Behavioral strategies included reducing or "cutting-back" smoking rates prior to quitting, changing environments, and changing brands.

\section{Discussion}

This study examined the gender differences in smoking behavior and cessation in adults. Although it was found that the majority of participants were motivated to quit and had the confidence to do so, provided they have help, the barriers faced differed between genders. Females were most likely to quote stress as the biggest barriers to quitting. Our results supported prior research that women are most likely to continue to smoke because of stress. ${ }^{[9,12]}$ Finding ways to help women reduce stress may help them in their fight to quit smoking and thus, improve abstinent rate for this population. Practice implications for women include the use of behavioral therapy/counseling for stress reduction in women. Counseling is an effective tool for smoking cessation. ${ }^{[19]}$ Behavioral therapy may include telephone, individual, and group counseling in stress reduction for women. Counseling by nurses and advanced practice nurses can provide professional support to help develop coping skills and provide stress reduction techniques. ${ }^{[19]}$ The authors developed an eight week counseling program for women as part of a multifaceted program. Each week participants met with the researchers to discuss difficulties with smoking cessation and receive counseling and group support. Each session had a 30minutes structured topic and time for questions and answers by the researchers and group support. The weekly counseling sessions contributed to less weight gain and higher smoking cessation rates at the end of the eight weeks. ${ }^{[6]}$

On the other hand, men, in this study, reported that although stress did play a part in their ability to quit smoking, other factors were an issue as well. The current research supported prior research that most men craved a cigarette when they saw others smoking combined with stress or boredom. ${ }^{[8]}$ Finding ways to help men conquer their cravings around others who smoke and reducing stress may help them in their

Published by Sciedu Press fight to quit, and thus, improve abstinent rates for this population. Practice implications for men include the use of a "quit buddy" or person to assist the man when he has the urge to smoke. Individual counseling for men can be effective in reducing stress. As men become comfortable with the "quit buddy", then they can move to group counseling sessions.

This study had several limitations. Participants were residents of a large metropolitan city, thus generalizability of the findings may be limited. Also, they wanted to quit smoking, which may have influenced the findings. Those who did not wish to quit smoking might encounter different barriers. Another limitation was that the study population was mostly Caucasian and African American. Results obtained may have been different for other ethnicities. Lastly, answers were not fully expanded upon. If questioned further, participants may have elicited more details on the barriers they faced.

Nevertheless, the findings make important additions to the current literature on gender differences in regard to smoking cessation. Men and women want to quit, but all smokers make several attempts before quitting. ${ }^{[2]}$ In our study, the barriers to successfully quitting differed between the genders. Treatment interventions need to be tailored to gender so that greater success and abstinent rates can be achieved. To reduce the barriers, the development of evidence-based tobacco cessation interventions is needed. An integration of approaches using pharmacology, counseling, and other multi-faceted interventions such as exercise are effective interventions for smoking cessation. Health promotion is primary for goals nurses seek to accomplish for patients who want to quit smoking.

\section{Conclusion}

Smoking cessation rates remain low in the population of adults in the United States. It is important for nurses to identify treatment modalities that can improve smoking cessation rates for both men and women. Smoking cessation should be promoted as part of a healthy lifestyle by the nursing and health care community. Nurses can use the findings of this study to implement gender-specific evidence-based interventions in the community and ambulatory settings. When men and women who smoke see a healthcare provider, they may leave the office without being assessed or treated for smoking cessation. Nurses and advanced practice nurses are in unique positions to provide smoking cessation for men and women. Smoking cessation interventions should be offered to all tobacco users during each visit with individualized plans for each patient. ${ }^{[19]}$

\section{ACKNOWLEDGeMENTS}

The authors wish to acknowledge the contributions of James 
E. Grobe, $\mathrm{PhD}$, in providing an independent qualitative analy- CONFLICTS OF INTEREST DiSCLOSURE sis of the interview data, assisting with quantitative analyses, The authors declare no competing interests. preparing final results, and revising the manuscript text.

\section{REFERENCES}

[1] Centers for Disease Control and Prevention. Adult cigarette smoking in the United States: current estimates [Internet]. 2014 Feb [cited 2014 Jun 4]. Available from: http://www.cdc.gov/tobacco/data_statistics/fact _sheets/adult_data/cig_smoking/index.htm

[2] Torchalla I, Okoli CTC, Hemsing N, et al. Gender differences in smoking behavior and cessation. J Smok Cessat. 2011 Apr; 6(1): 9-16. http://dx.doi.org/10.1375/jsc.6.1.9

[3] American Lung Association. Women and tobacco use [Internet]. [cited 2014 Jun]. Available from: http: //www.lung.org/stop-smoking/about-smoking/facts -figures/women-and-tobacco-use.html

[4] Paddock C. Female smokers at higher risk of heart disease. Medical News Today [Internet]. 2011 Aug 11 [cited 2014 Jun 4]. Available from: http://www.medicalnewstoday.com/article s/232604.php

[5] Piper ME, Cook JW, Schlam TR, et al. Gender, race, and education differences in abstinence rates among participants in two randomized smoking cessation trials. Nicotine Tob Res. 2010 May 10; 12(6): 647-52. PMID:20439385. http://dx.doi.org/10.1093/ntr/n tq067

[6] Chaney S, Sheriff S. Weight gain among women during smoking cessation. AAOHN J. 2008 Mar; 56(3): 99-105. PMID:18389822. http://dx.doi.org/10.3928/08910162-20080301-04

[7] Fidler JA, West R. Self-perceived smoking motives and their correlates in a general population sample. Nicotine Tob Res. 2009 Oct; 11(10): 1182-8. PMID:19640835. http://dx.doi.org/10.1093 $/ n t r / n t p 120$

[8] Moffatt J, Whip R. The struggle to quit: barriers and incentives to smoking cessation. Health Educ J. 2004 Jun; 63(2): 101-12. http://dx.doi.org/10.1177/001789690406300202

[9] Saladin ME, Gray KM, Carpenter MJ, et al. Gender differences in craving and cue reactivity to smoking and negative affect/stress cues. Am J Addict. 2012 May; 21(3): 210-20. PMID:22494223. http://dx.doi.org/10.1111/j.1521-0391.2012.00232.x

[10] Pineiro B, Lopez-Duran A, Fernandez DR, et al. Gender differences in personality patterns and smoking status after a smoking cessation treatment. BMC Public Health. 2013 Apr 8; 13(306): 1-10.
[11] McKee SA, O'Malley SS, Salovey P, et al. Perceived risks and benefits of smoking cessation: gender-specific predictors of motivation and treatment outcome. Addict Behav. 2005 Mar; 30(3): 423-35. PMID:15718060. http://dx.doi.org/10.1016/j.addbeh. 20 04.05 .027

[12] Tod AM. Barriers to smoking cessation in pregnancy: a qualitative study. Br J Community Nurs. 2003 Feb; 8(2): 56-64. PMID:12589246. http://dx.doi.org/10.12968/bjen. 2003. 8.2.11088

[13] Twyman L, Bonevski B, Paul C, et al. Perceived barriers to smoking cessation in selected vulnerable groups: a systematic review of the qualitative and quantitative literature. BMJ Open. 2014 Dec 22; 4(12): 1-16. PMID:25534212. http://dx.doi.org/10.1136/bmjopen $-2014-006414$

[14] Rosenthal L, Carroll-Scott A, Earnshaw VA, et al. Targeting cessation: understanding barriers and motivations to quitting among urban adult daily tobacco smokers. Addict Behav. 2013 Mar; 38(3): 163942. PMID:23254211. http://dx.doi.org/10.1016/j.addbeh . 2012.09 .016

[15] Graneheim UH, Lundman B. Qualitative content analysis in nursing research: concepts, procedures and measures to achieve trustworthiness. Nurse Educ Today. 2004 Feb; 24(2): 105-12. PMID:14769454 http://dx.doi.org/10.1016/j.nedt.2003.10.001

[16] Elo $S$, Kyngas $H$. The qualitative content analysis process. J Adv Nurs. 2008 Apr; 62(1): 107-15. PMID:18352969. http://dx. doi . org $/ 10.1111 / j .1365-2648.2007 .04569 . x$

[17] Pope C, Ziebland S, Mays N. Qualitative research in health care: analysing qualitative data. BMJ. 2000 Jan 8; 320(7227): 114-6. PMID:10625273. http://dx.doi.org/10.1136/bmj . 320.722 7.114

[18] Patten CA, Enoch C, Renner CC, et al. Focus groups of Alaska Native adolescent tobacco users: preferences for tobacco cessation interventions and barriers to participation. Health Educ Behav. 2009 Aug; 36(4): 711-23. PMID:18048549. http://dx.doi.org/10. $1177 / 1090198107309456$

[19] Chaney S, Sheriff S. Evidence-based treatments for smoking cessation. Nurse Pract. 2012 Apr 15; 37(4): 24-31. PMID:22395743. ht tp://dx.doi.org/10.1097/01.NPR.0000412892.27557.e8 